Article

\title{
Electron Microscopic Confirmation of Anisotropic Pore Characteristics for ECMO Membranes Theoretically Validating the Risk of SARS-CoV-2 Permeation
}

\author{
Makoto Fukuda ${ }^{1, *(D)}$, Tomoya Furuya ${ }^{1}$, Kazunori Sadano ${ }^{1}$, Asako Tokumine ${ }^{1}$, Tomohiro Mori ${ }^{2}$ (D), \\ Hitoshi Saomoto ${ }^{2}$ and Kiyotaka Sakai ${ }^{3}$
}

Citation: Fukuda, M.; Furuya, T.; Sadano, K.; Tokumine, A.; Mori, T.; Saomoto, H.; Sakai, K. Electron Microscopic Confirmation of Anisotropic Pore Characteristics for ECMO Membranes Theoretically Validating the Risk of SARS-CoV-2 Permeation. Membranes 2021, 11, 529. https://doi.org/10.3390/membranes 11070529

Academic Editor: Fabio Silvio Taccone

Received: 24 May 2021

Accepted: 12 July 2021

Published: 14 July 2021

Publisher's Note: MDPI stays neutral with regard to jurisdictional claims in published maps and institutional affiliations.

Copyright: (c) 2021 by the authors. Licensee MDPI, Basel, Switzerland. This article is an open access article distributed under the terms and conditions of the Creative Commons Attribution (CC BY) license (https:/ / creativecommons.org/licenses/by/ $4.0 /)$.
1 Department of Biomedical Engineering, Kindai University, 930 Nishimitani, Kinokawa-city, Wakayama 649-6493, Japan; to1mo1ya7.f@gmail.com (T.F.); 1718360065r@waka.kindai.ac.jp (K.S.); tokumine@waka.kindai.ac.jp (A.T.)

2 Industrial Technology Center of Wakayama Prefecture, 60 Ogura, Wakayama-city, Wakayama 649-6261, Japan; tomohiro_mori@wakayama-kg.jp (T.M.); saomoto@wakayama-kg.jp (H.S.)

3 Department of Chemical Engineering, Waseda University, 3-4-1 Okubo, Shinjuku-ku, Tokyo 169-8555, Japan; kisakai@waseda.jp

* Correspondence: fukuda@waka.kindai.ac.jp

\begin{abstract}
The objective of this study is to clarify the pore structure of ECMO membranes by using our approach and theoretically validate the risk of SARS-CoV-2 permeation. There has not been any direct evidence for SARS-CoV-2 leakage through the membrane in ECMO support for critically ill COVID19 patients. The precise pore structure of recent membranes was elucidated by direct microscopic observation for the first time. The three types of membranes, polypropylene, polypropylene coated with thin silicone layer, and polymethylpentene (PMP), have unique pore structures, and the pore structures on the inner and outer surfaces of the membranes are completely different anisotropic structures. From these data, the partition coefficients and intramembrane diffusion coefficients of SARS-CoV-2 were quantified using the membrane transport model. Therefore, SARS-CoV-2 may permeate the membrane wall with the plasma filtration flow or wet lung. The risk of SARS$\mathrm{CoV}-2$ permeation is completely different due to each anisotropic pore structure. We theoretically demonstrate that SARS-CoV-2 is highly likely to permeate the membrane transporting from the patient's blood to the gas side, and may diffuse from the gas side outlet port of ECMO leading to the extra-circulatory spread of the SARS-CoV-2 (ECMO infection). Development of a new generation of nanoscale membrane confirmation is proposed for next-generation extracorporeal membrane oxygenator and system with long-term durability is envisaged.
\end{abstract}

Keywords: extracorporeal membrane oxygenator (ECMO); artificial lung; extracorporeal membrane oxygenation (ECMO); COVID-19; plasma leakage; ECMO infection; polypropylene (PP); silicone layer; polymethylpentene (PMP)

\section{Introduction}

Hollow fiber membrane oxygenator (artificial lung) is used for cardiovascular surgery such as coronary artery bypass surgery, valve replacement, and implantable artificial heart surgery. It is also incorporated into the extracorporeal membrane oxygenation (ECMO) system [1-8], which treats severe acute respiratory distress syndrome due to the novel coronavirus disease 2019 (COVID-19). The extracorporeal membrane oxygenator (ECMO) is said to be the "last stronghold" for critically ill patients with COVID-19 [1].

The most serious dysfunctions in ECMO are the increased excessive pressure drop in blood flow path, plasma leakage, and decrease in gas exchange rate [4-8]. In addition, as blood coagulation and thrombus are generated in severely ill patients with COVID-19 [9], incidents have been reported in which a blood flow path of membrane oxygenator is 
easily clogged in ECMO treatment. There is a concern that the treatment for critically ill COVID-19 patients causes more serious excessive pressure drop.

On the other hand, plasma leakage frequently occurs in extracorporeal membrane oxygenation $(\mathrm{ECMO})$ when used in respiratory support therapy $[4,5]$, which requires more time than when being used in cardiovascular surgery. When the ECMO membrane pores are in contact with blood for a long time, the hydrophobicity of the membrane is gradually impaired and the membrane becomes hydrophilic, the air in the pores is replaced with plasma, and plasma leaks to the gas side. If plasma leakage occurs, not only is the gas exchange efficiency lowered, but the water balance of the patient is also disturbed and, in the worst case, the patient may be in a critical condition [3]. Even in the case of such an incident, at present, an operator such as a clinical engineer takes measures such as replacing it with an unused membrane oxygenator before an accident occurs.

It has been reported that plasma components in the blood leak into the lumen of hollow fiber membrane (plasma leakage) and yellow foam leaks from the gas outlet port of a membrane oxygenator during an ECMO treatment for critically ill patients with COVID-19 [2]. There is a concern that SARS-CoV-2 in plasma may permeate through the pore in the membrane and diffuse as an aerosol from the gas outlet port, which is still one of the issues in operating ECMO.

The pore structure of the gas exchange membrane for ECMO and the mechanism of plasma leakage have been studied so far [3-5]. However, the membrane and pore structures of the recent ECMO membranes have not been clarified, and the permeability of solutes such as viruses through the membrane has not been investigated.

The objective of this study is to clarify the pore structure of ECMO membranes by using our approach for analyzing membrane pore structures by scanning probe microscope (SPM) and field emission scanning electron microscope (FE-SEM) [10-16]. Then, the permeability of SARS-CoV-2 through the membrane is evaluated using the steric exclusion model and hindered diffusion model, which are simple permeation theories in membrane science. We suggest the development of a new generation of nanoscale membrane confirmation to prevent extra-circulatory spread of the SARS-CoV-2.

\section{Material and Methods}

\subsection{Hollow Fiber Membrane for Extracorporeal Membrane Oxygenator}

The samples studied were commercially available extracorporeal membrane oxygenators, which are typical in Japan. These are the outside blood flow oxygenators. They contribute to ECMO systems in cardiovascular surgery and in the treatment of severe acute respiratory distress syndrome, both in Japan and around the world. Table 1 shows the technical data of the samples.

oxia ${ }^{\circledR}$ ACF (JMS Co., Ltd., Hiroshima, Japan, Sample A) equips a hollow fiber membrane made of polypropylene and is approved as Extracorporeal Membrane Oxygenator (ECMO) in Japan. The MERA NHP ${ }^{\circledR}$ (SENKO MEDICAL INSTRUMENT Mfg. Co., Ltd., Tokyo, Japan, Sample B) is a hollow fiber membrane made of polypropylene coated with a silicone layer on the outer surface. Sample B is approved as ECMO and ECMO for assisting respiration. BIOCUBE ${ }^{\circledR}$ (Nipro Co., Ltd., Tokyo, Japan, Sample C) is a polymethylpentene (PMP) membrane. This is the first PMP membrane for artificial lung worldwide. Sample $\mathrm{C}$ is approved as ECMO and ECMO for assisting respiration. The manufacturing approval standard (requirement) [17] of ECMO for assisting respiration is that "the membrane characteristics of a silicone membrane or a special polyolefin membrane can prevent plasma leakage". 
Table 1. Specification of hollow fiber membranes for membrane oxygenators.

\begin{tabular}{|c|c|c|c|}
\hline Sample & $\begin{array}{l}\text { oxia }^{\circledR} \text { ACF } \\
\text { Sample A }\end{array}$ & $\begin{array}{c}\text { MERA NHP }{ }^{\circledR} \text { Exelung TPC } \\
\text { HPO-23WH-C } \\
\text { Sample B }\end{array}$ & $\begin{array}{l}\text { BIOCUBE }^{\circledR} 6000 \\
\text { Sample C }\end{array}$ \\
\hline $\begin{array}{c}\text { Manufacturer } \\
\text { (Manufacturer of membrane) }\end{array}$ & $\begin{array}{c}\text { JMS Co., Ltd., } \\
\text { Hiroshima, Japan } \\
\text { (3M Co., Ltd., USA) }\end{array}$ & $\begin{array}{c}\text { SENKO MEDICAL } \\
\text { INSTRUMENT Mfg. CO., Ltd., } \\
\text { Tokyo, Japan }\end{array}$ & $\begin{array}{l}\text { Nipro Co., Ltd., Tokyo, Japan } \\
\text { (DIC Co., Ltd., Tokyo, Japan) }\end{array}$ \\
\hline $\begin{array}{l}\text { Material of hollow fiber } \\
\text { membrane }\end{array}$ & Polypropylene (PP) & Polypropylene (PP), silicone & Polymethylpentene (PMP) \\
\hline $\begin{array}{l}\text { Antithrombogenic material } \\
\text { coating for blood flow channel }\end{array}$ & $\begin{array}{c}\text { Poly } \\
\text { (2-methacryloyloxyethyl } \\
\text { phosphoryl choline) (PMPC) }\end{array}$ & Heparin compound & Heparin \\
\hline $\begin{array}{l}\text { Inner diameter of lumen }[\mu \mathrm{m}] \\
\qquad(\mathrm{n}=30)\end{array}$ & $238 \pm 5$ & $246 \pm 3$ & $176 \pm 6$ \\
\hline $\begin{array}{l}\text { Membrane thickness }[\mu \mathrm{m}](\mathrm{n} \\
=30)\end{array}$ & $35 \pm 1$ & $27 \pm 1$ & $30 \pm 2$ \\
\hline Air permeability ${ }^{(1)}[\mathrm{s}]$ & $35.1 \pm 1.4$ & - & - \\
\hline Pore structure & asymmetric pore structure & $\begin{array}{l}\text { asymmetric pore structure, the } \\
\text { outer surface of the membrane } \\
\text { is coated with thin silicone layer } \\
\text { (thickness } 0.2 \mu \mathrm{m} \text { ) }\end{array}$ & asymmetric pore structure \\
\hline Sterilization method & EOG & EOG & EOG \\
\hline $\begin{array}{l}\text { Insurance coverage } \\
\text { classification (in Japan) }\end{array}$ & $\begin{array}{l}\text { extracorporeal membrane } \\
\text { oxygenator; ECMO }^{(2)}\end{array}$ & $\begin{array}{c}\text { extracorporeal membrane } \\
\text { oxygenator; ECMO }{ }^{(2)} \text { Cardiac } \\
\text { ECMO } \\
\text { Respiratory ECMO }\end{array}$ & $\begin{array}{c}\text { extracorporeal membrane } \\
\text { oxygenator; ECMO }^{(2)} \text { Cardiac } \\
\text { ECMO } \\
\text { Respiratory ECMO }\end{array}$ \\
\hline
\end{tabular}

(1) The gas permeability of the membranes was measured by the Gurley method using an air resistance tester defined in ISO5636-5 [18]. The smaller the value, the larger the gas permeability; ${ }^{(2)}$ Usage time $6 \mathrm{~h}$; ${ }^{(3)}$ Usage time $6 \mathrm{~h}$, the membrane characteristics of a silicone membrane or a special polyolefin membrane can prevent plasma leakage.

\subsection{Observation of Three-Dimensional Tortuous Pore Using Scanning Probe Microscope (SPM) System}

The method reported in our previous study $[15,16]$ was employed to observe the inner and outer surfaces of hollow fiber membranes.

A sample, as shown in Figure 1, was prepared in order to observe the inner surface of the hollow fiber membrane (dry). A flat surface without curvature was created to improve the accuracy of the image. When observing the outer surface of the hollow fiber, a sample having a low sample height was prepared and a flat surface was observed. Three or more samples were observed, and a representative image was shown in the result.

\subsection{Observation of Three-Dimensional Tortuous Pores Using Field Emission Scanning Electron Microscope (FE-SEM)}

For a comparative verification against the SPM, followed by the design validation, we used a FE-SEM (JSM-7610F, Jeol Ltd., Tokyo, Japan) to observe the inner and outer surfaces of the hollow fiber membranes at an accelerating voltage of $1.5 \mathrm{kV}$, a working distance of $4.5 \mathrm{~mm}$, and an emission current of $47.2 \mu \mathrm{A}$ [16]. No conductive treatment with Au or $\mathrm{C}$ was applied. Pore diameters were measured in observation fields of a magnification of 100,000 in size by the analysis of digital imagery utilizing ImageJ software (Naional Institute of Mental Health, Bethesda, MD, USA). 

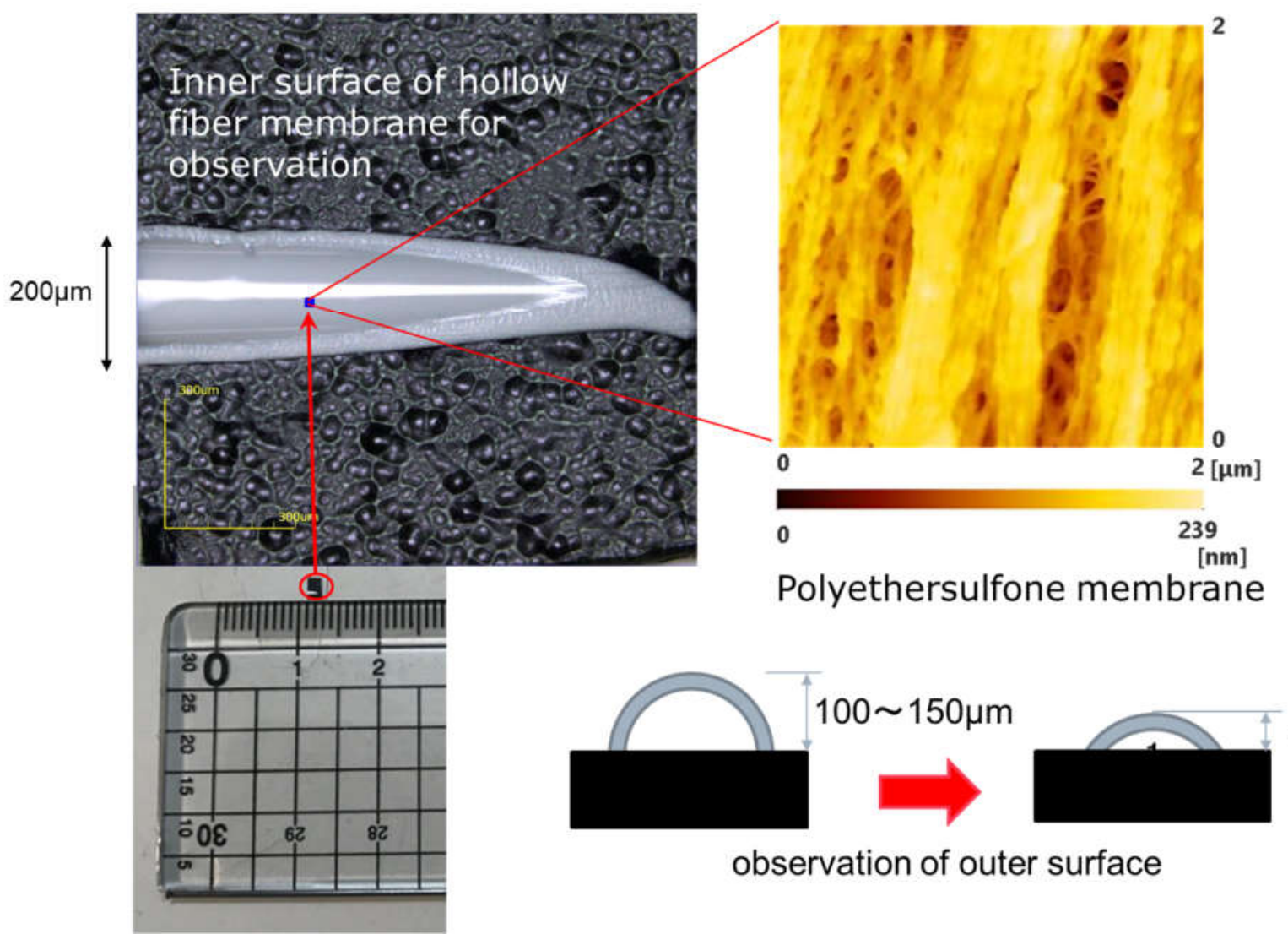

Polyethersulfone membrane

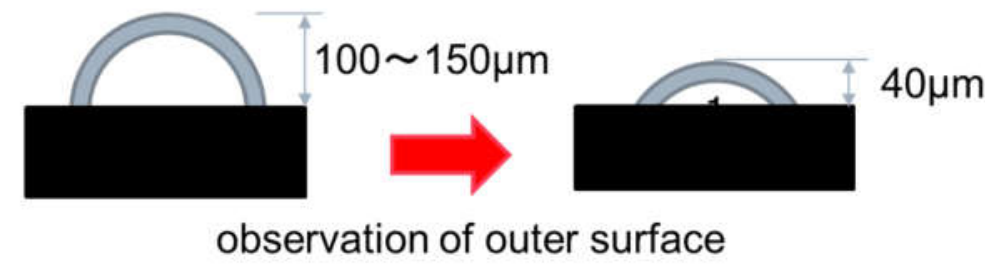

Figure 1. Inner surface of hollow fiber membrane used for observation (LEXT OLS4000, 3D measurement laser microscope, Olympus Co., Ltd., Tokyo, Japan) [15,16].

2.4. Validation of SARS-CoV-2 Permeability Using the Steric Exclusion Model and Hindered Diffusion Model

An attempt was made to quantify the membrane permeability for the SARS-CoV-2 using the steric exclusion model and hindered diffusion model [19].

The diffusive coefficient of SARS-CoV-2 in water was calculated by Equation (1) expressing the Stokes-Einstein relationship.

$$
D_{A B}=\frac{R T}{6 \pi \mu a N_{A}}
$$

where $R$ is the ideal gas constant, $T$ is the absolute temperature, a is the solute radius, $N_{A}$ is Avogadoro's number $\left(6.02 \times 10^{23} \mathrm{~mol}^{-1}\right)$, and $\mu$ is the solution viscosity.

The diffusive coefficient of SARS-CoV-2 in plasma at $37^{\circ} \mathrm{C}$ was calculated in consideration of the increase in plasma viscosity relative to the viscosity of water.

$$
D_{\text {plasma }}=D_{A B} \times\left(\frac{0.697 c P}{1.19 c P}\right)=0.586 D_{A B}
$$

where the plasma temperature was set to $37^{\circ} \mathrm{C}$ assuming extracorporeal circulation.

Therefore, the fraction of the pore cross-sectional area through which the solute penetrates is given by Equation (3).

$$
K=\frac{\pi(r-a)^{2}}{\pi r^{2}}=\left(1-\frac{a}{r}\right)^{2}=\frac{C_{\text {Apore }}}{C_{\text {Abulk }}}
$$

where $K$ is known as the solute partition coefficient, $a$ is molecular radius, $r$ is pore radius, and $C_{A}$ is solute concentration. 
Mass transfer flux in a pore is given by Equation (4) from the Fick's first law applicable to a dilute solution.

$$
N_{A x}^{\text {pore }}=-D_{\text {pore }} \frac{d C_{\text {Apore }}}{d x}=-D_{\text {pore }} \frac{C_{\text {Apore }}^{x=\bar{L}}-C_{\text {Apore }}^{x=0}}{\bar{L}}
$$

where $D_{\text {pore }}$ is diffusive coefficient in a pore, $\bar{L}$ is membrane thickness, and $C_{\text {Apore }}$ is solute concentration in a pore.

The solute concentrations in the pore at the inlet and outlet of the pore are related with the bulk solute concentrations just outside the pore by the partition coefficient. Therefore, Equation (4) is expressed as Equation (5).

$$
N_{A x}^{\text {pore }}=-D_{\text {pore }} \frac{d C_{\text {Apore }}}{d x}=-D_{\text {pore }} K \frac{C_{A b i l k}^{x=\bar{L}}-C_{A b u l k}^{x=0}}{\bar{L}}
$$

The tortuous nature of the pore is explained by using the tortuosity $(\tau)$ for the actual pore length $(\tau \times \bar{L})$.

In addition, as the hindered diffusion affects the permeation of the solute in the pores, the value of $D_{\text {pore }}$ is smaller than the value of $D_{A B}$ due to the parameter for the hindered diffusion $\left(\omega_{r}\right)$. The term for hindered diffusion $\left(\omega_{r}\right)$ depends on the ratio of the solute radius to the pore radius $(a / r)$. Therefore, Equation (5) can be expressed as Equation (6).

$$
N_{A x}^{\text {pore }}=-D_{\text {pore }} K \frac{C_{\text {Abulk }}^{x=\bar{L}}-C_{\text {Abulk }}^{x=0}}{\bar{L}}=-D_{A B}\left(\frac{K \omega_{r}}{\tau}\right) \frac{C_{A b u l k}^{x=\bar{L}}-C_{\text {Abulk }}^{x=0}}{\bar{L}}
$$

Equation (6) represents the mass transfer flux in a pore of a membrane in terms of the measurable bulk solute concentrations at the surface on both sides of the membrane. From Equation (6), the solute diffusive coefficient in the pore $\left(D_{\text {pore }}\right)$ and the solute diffusive coefficient across a membrane pore relative to the bulk solute concentration $\left(D_{m}\right)$ are defined as follows.

$$
\begin{gathered}
D_{\text {pore }}=D_{A B} \frac{\omega_{r}}{\tau} \\
D_{m}=K D_{\text {pore }}=D_{A B}\left(\frac{K \omega_{r}}{\tau}\right)
\end{gathered}
$$

From previous studies [20,21], $K \omega_{r}$ is only a function of $\lambda=a / r$. This is given by Equation (9).

$$
K \omega_{r}=\left(1-\frac{a}{r}\right)^{2}\left[1-2.1\left(\frac{a}{r}\right)+2.09\left(\frac{a}{r}\right)^{3}-0.95\left(\frac{a}{r}\right)^{5}\right]
$$

The term $\left(1-\frac{a}{r}\right)^{2}$ on the right-hand side of Equation (9) is the partition coefficient (K) by Equation (3). The term on the right-hand side of Equation (9) is the hindered diffusion parameter $\left(\omega_{r}\right)$ by Equation (10).

$$
\omega_{r}=\left[1-2.1\left(\frac{a}{r}\right)+2.09\left(\frac{a}{r}\right)^{3}-0.95\left(\frac{a}{r}\right)^{5}\right]
$$

$\omega_{r}$ represents the increased hydrodynamic drag in the pore comparable in size to that of the solute.

\section{Results}

\subsection{SPM Observations of Tortuous Pore Structures of ECMO Membranes}

Figure $2 a, b$ show the results of the observations of oxia ${ }^{\circledR}$ (dry, sample A), (a) the surface of inner lumen of the capillary membranes, and (b) the outer surface of the capillary membranes. In addition, (1), (2), and (3) show the scanning areas of $2000 \mathrm{~nm} \times 2000 \mathrm{~nm}$, 
$500 \mathrm{~nm} \times 500 \mathrm{~nm}$, and $200 \mathrm{~nm} \times 200 \mathrm{~nm}$, respectively. The image of (3) shows magnified images of the pores enclosed by the blue square in (2), and the image of (2) shows magnified images of the pores enclosed by the blue square in (1). The color gradient bar at the bottom represents the scale in the $\mathrm{Z}$-direction of the image.

(a1)

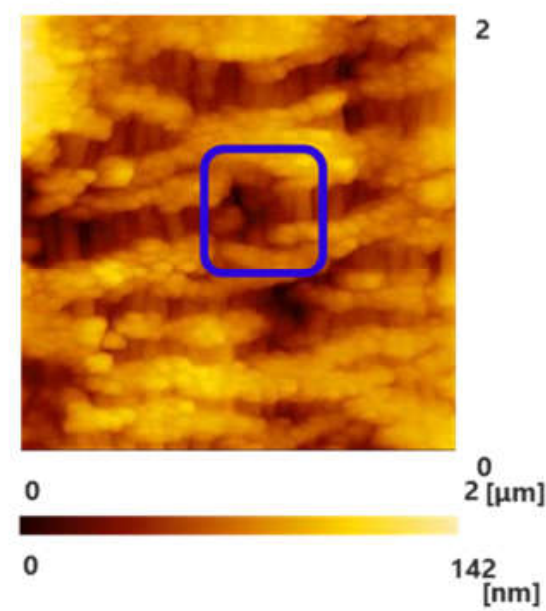

(b1)

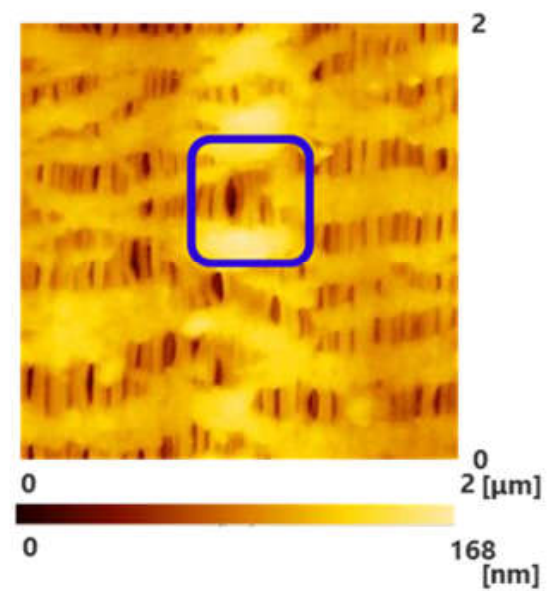

(a2)

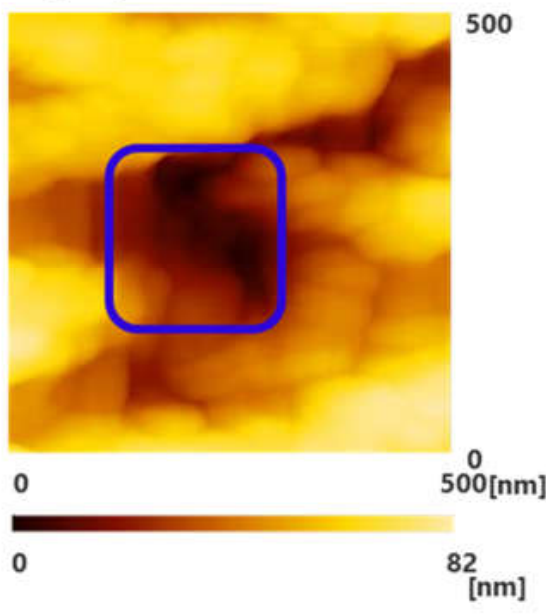

(b2)

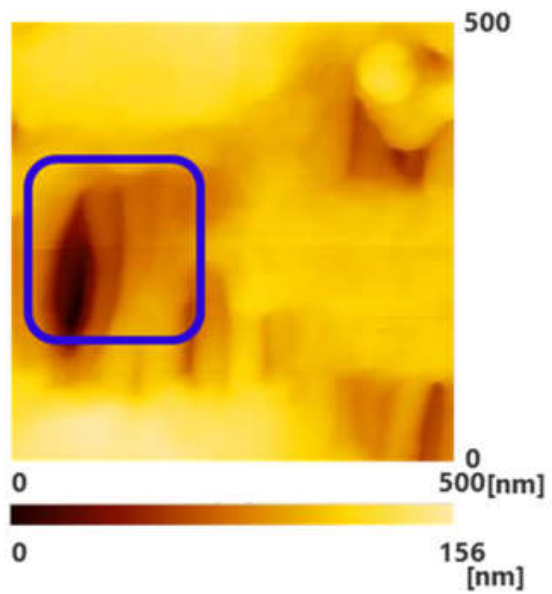

(a3)

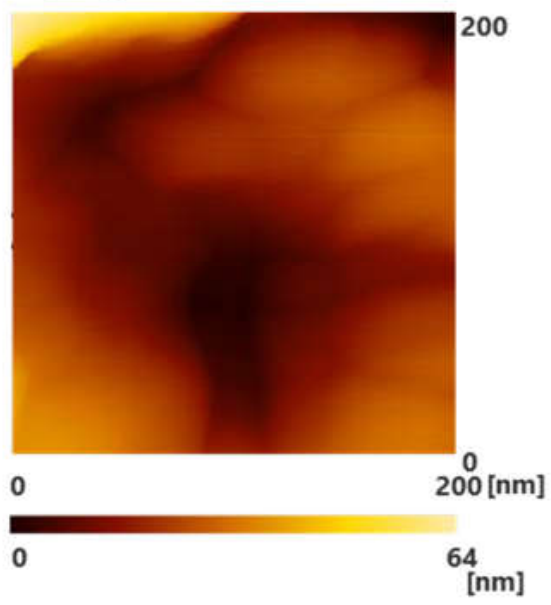

(b3)

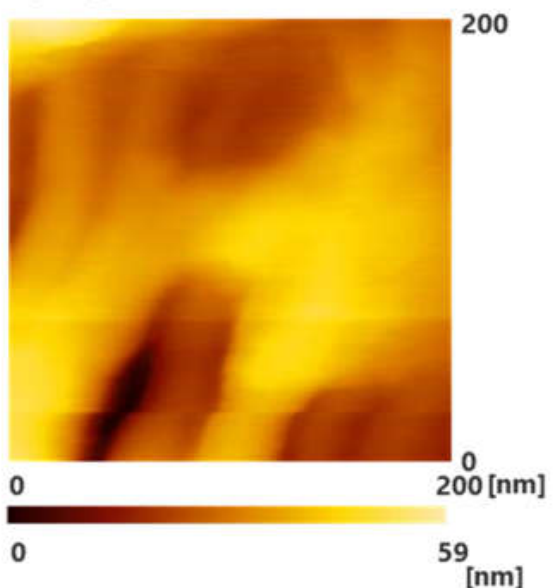

Figure 2. Scanning probe microscopy (SPM) images of oxia ${ }^{\circledR}(\mathrm{dry}),(\mathbf{a})$ the surface of inner lumen of the capillary membrane, and (b) the outer surface of the capillary membrane: (1) $2000 \mathrm{~nm} \times 2000 \mathrm{~nm}$; (2) $500 \mathrm{~nm} \times 500 \mathrm{~nm}$; and (3) $200 \mathrm{~nm} \times 200 \mathrm{~nm}$, respectively. The image of (3) shows magnified images of the pores enclosed by the blue square in (2), and the image of (2) shows magnified images of the pores enclosed by the blue square in (1).

On the surface of the hollow fiber membrane of sample A, the unique pore structure stretched in an elliptical shape in the longitudinal direction of the hollow fiber membrane was observed.

Images for the pore structures of ECMO membranes were obtained using SPM, but the images were unclear. Compared with the images of hemoconcentrator membranes and hemodialysis membranes (polyether sulfone) $[15,16]$ in our previous studies, we could not observe clear three-dimensional tortuous pore structures of membranes. Therefore, we decided that an analysis by another approach was necessary.

\subsection{FE-SEM Observations of Tortuous Pore Structures of ECMO Membranes}

Figure 3 is FE-SEM images of oxia ${ }^{\circledR}$ (dry), (a) the surface of inner lumen of the capillary membranes, (b) the outer surface of the capillary membranes: $(1) \times 30,000$; $(2) \times 50,000$; 
and (3) $\times 100,000$, respectively. The image of (3) shows magnified images of the pores enclosed by the blue square in (2), and the image of (2) shows magnified images of the pores enclosed by the blue square in (1).

(a1)

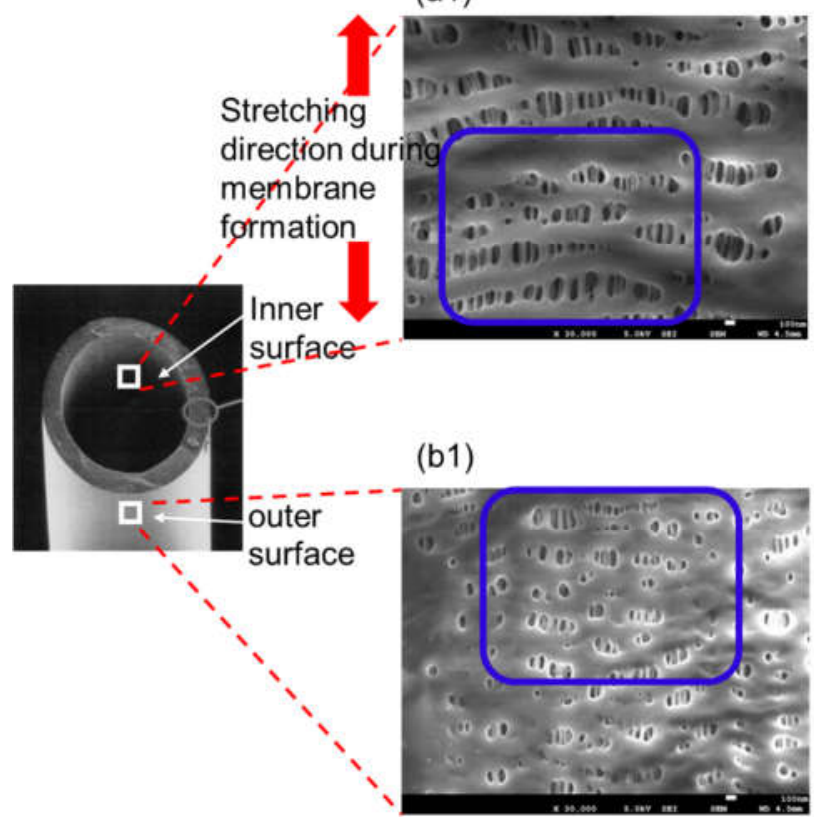

(a2)

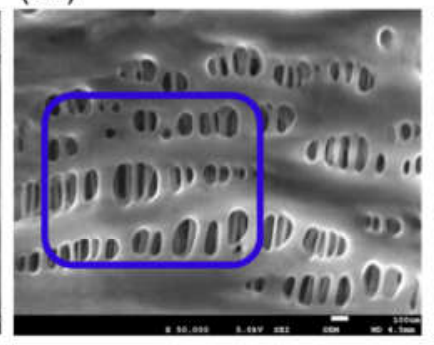

(b2)

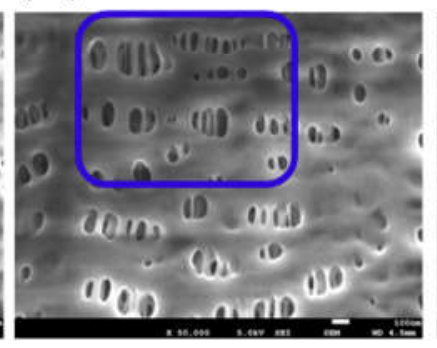

(a3)

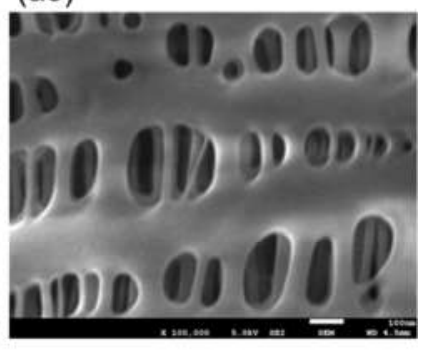

(b3)

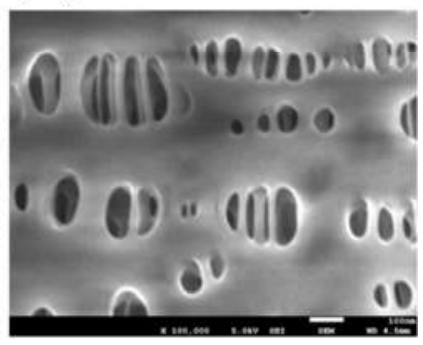

Figure 3. FE-SEM images of oxia ${ }^{\circledR}$ (dry), (a) the surface of inner lumen of the capillary membranes, (b) the outer surface of the capillary membranes: (1) $\times 30,000$; (2) $\times 50,000$; and (3) $\times 100,000$, respectively. The image of (3) shows magnified images of the pores enclosed by the blue square in (2), and the image of (2) shows magnified images of the pores enclosed by the blue square in (1).

On the inner and outer surfaces of the sample A, long elliptical pores were observed in the longitudinal direction of the hollow fiber membrane. The higher the magnification of the image, the deeper the pores could be confirmed, and the three-dimensional tortuous pore structure was confirmed. When polypropylene was stretched by the stretching method to form a hollow fiber membrane, the pores were also stretched in the longitudinal direction of the membrane. The pores on the outer surface were smaller than those on the inner surface. Compared with the SPM images shown in 3.1, the FE-SEM gave very clear images, and the unique pore structure of sample A was observed. For this reason, unlike our previous studies [15,16], FE-SEM is more useful for pore structure analysis of polypropylene ECMO membranes.

Figure 4 is FE-SEM images of MERA NHP ${ }^{\circledR}$ (dry), (a) the surface of inner lumen of the capillary membranes and (b) the outer surface of the capillary membranes.

Sample B is also made of polypropylene, and the pores on the inner surface of the membrane are stretched in the longitudinal direction of the membrane. On the other hand, as the outer surface of the membrane is coated with thin silicone layer, the pore structure is not confirmed. From these, sample B is a polypropylene membrane coated with silicone layer, and in the outside blood flow membrane oxygenator, the silicone layer comes into direct contact with blood. However, as shown in Figure 5, a structure in which the silicone layer was peeled off was partly confirmed on the outer surface of the membrane. 
(a1)

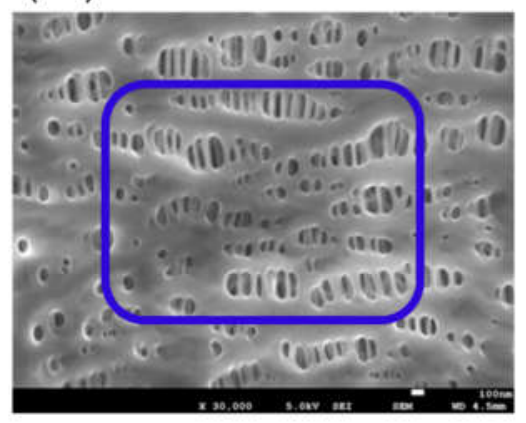

(b1)

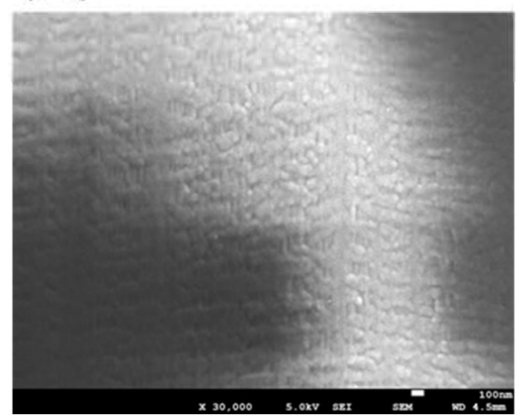

(a2)

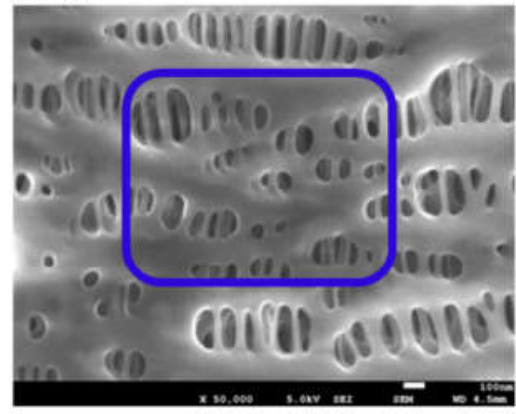

(b2)

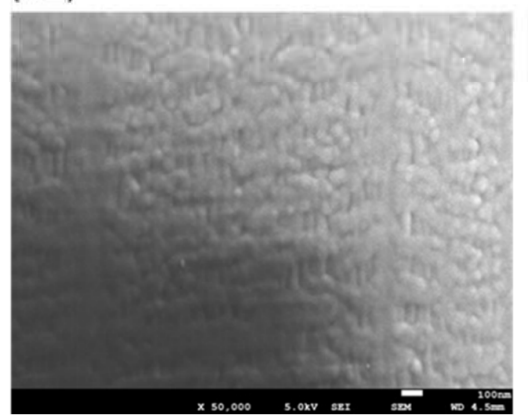

(a3)

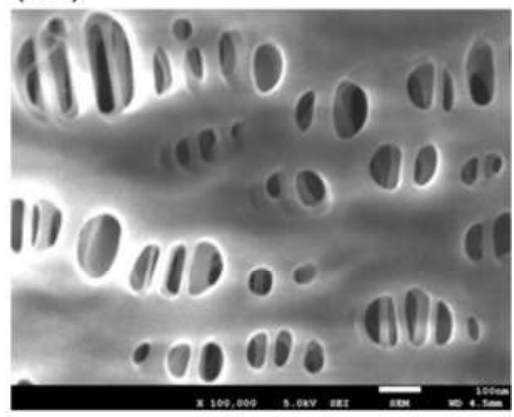

(b3)

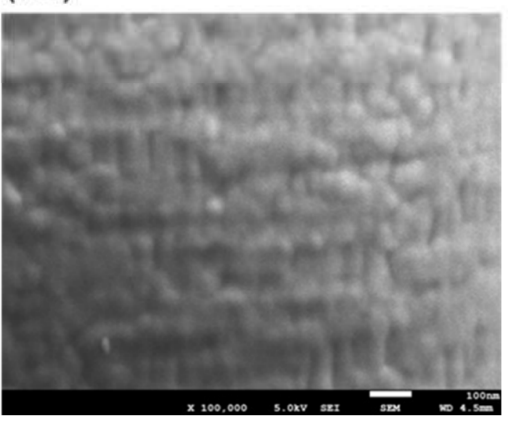

Figure 4. FE-SEM images of MERA NHP ${ }^{\circledR}$ (dry), (a) the surface of inner lumen of the capillary membranes, (b) the outer surface of the capillary membranes: $(1) \times 30,000$; (2) $\times 50,000$; and (3) $\times 100,000$, respectively. The image of (3) shows magnified images of the pores enclosed by the blue square in (2), and the image of (2) shows magnified images of the pores enclosed by the blue square in (1).

The part where the silicon coating is peeled off from the polypropylene membrane.

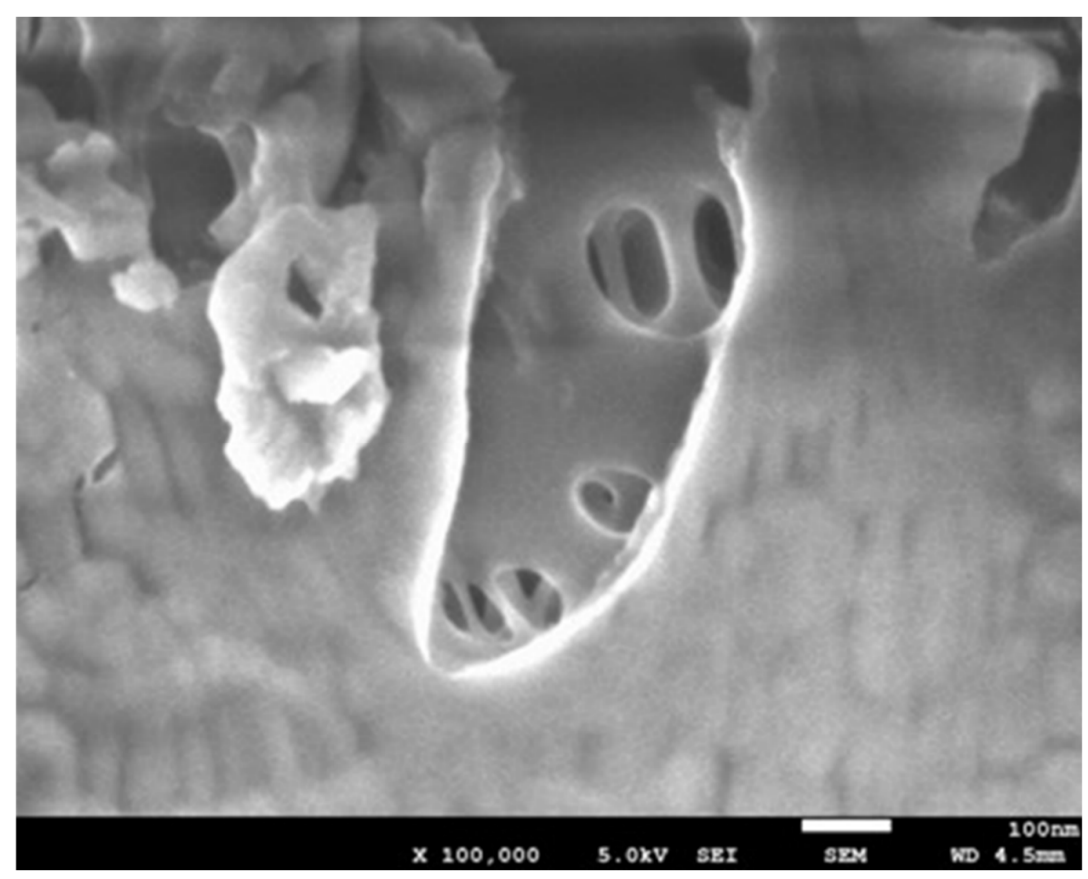

Figure 5. FE-SEM image of MERA NHP ${ }^{\circledR}($ dry), the outer surface of the capillary membranes; and $\times 100,000$.

Figure 6 is FE-SEM images of BIOCUBE ${ }^{\circledR}$ (dry), (a) the surface of inner lumen of the capillary membranes and $(b)$ the outer surface of the capillary membranes. 
(a1)

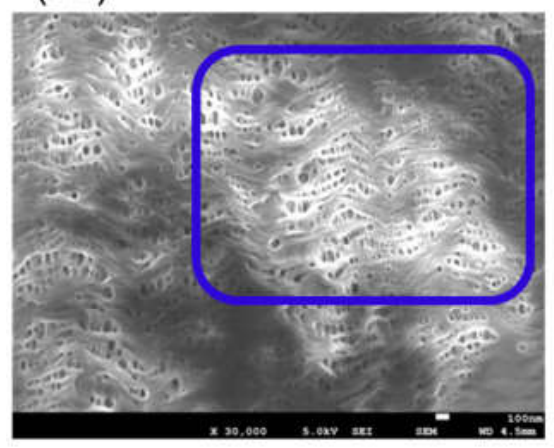

(a2)
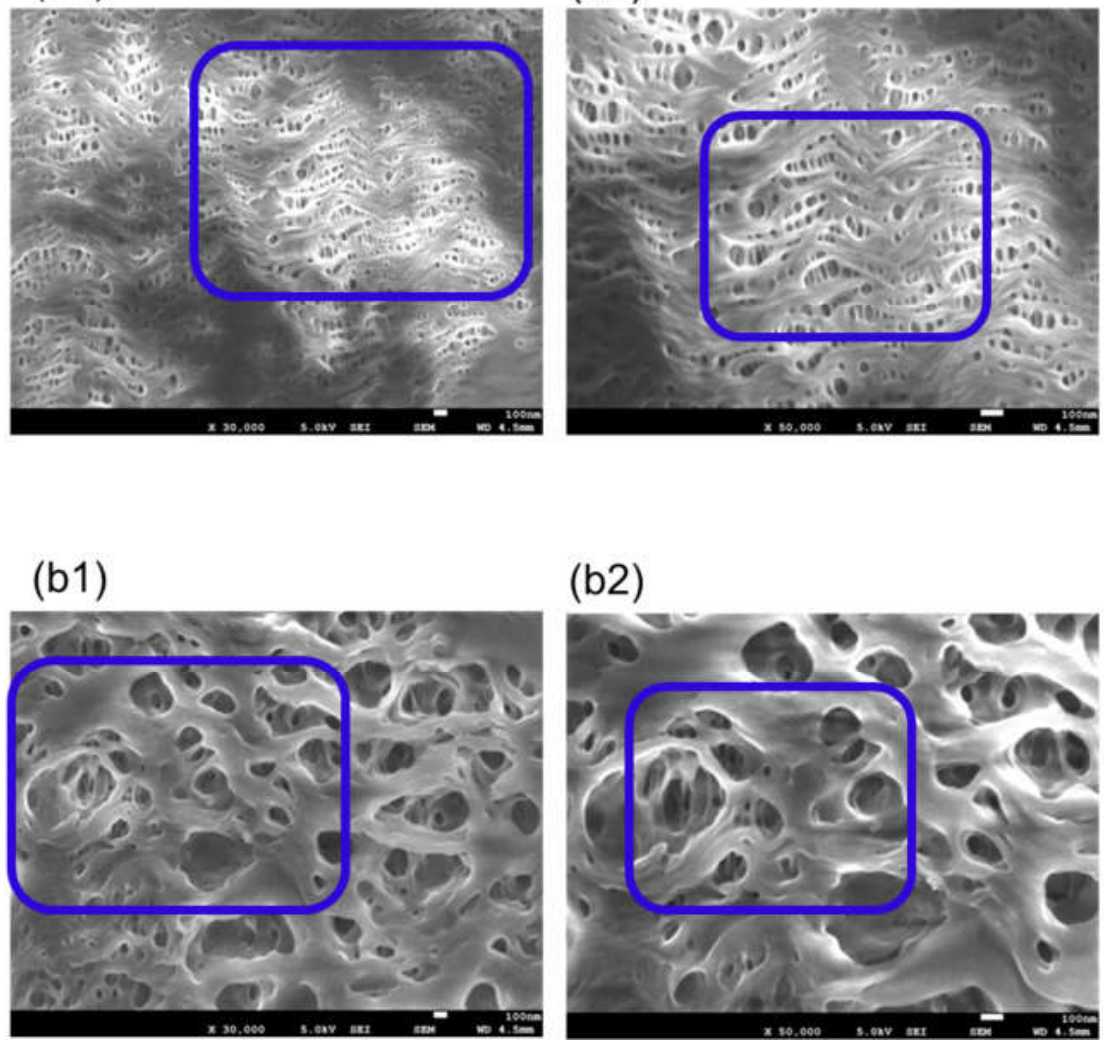

(b2)

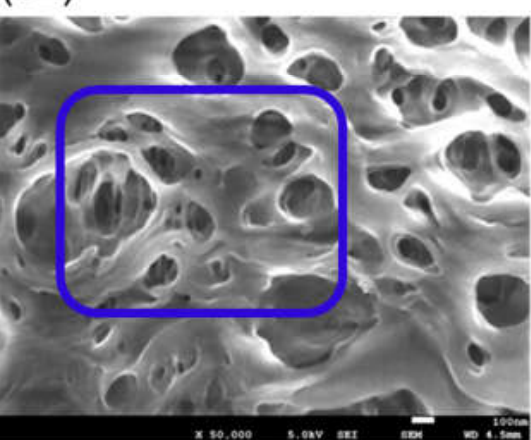

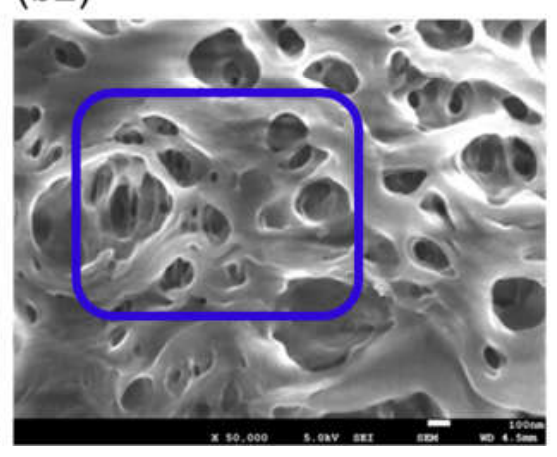

(b3)

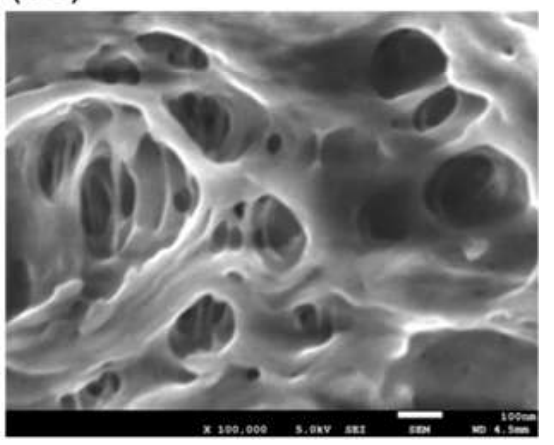

Figure 6. FE-SEM images of $\operatorname{BIOCUBE}^{\circledR}($ dry), (a) the surface of inner lumen of the capillary membranes and (b) the outer surface of the capillary membranes: $(1) \times 30,000$; $(2) \times 50,000$; and (3) $\times 100,000$, respectively. The image of (3) shows magnified images of the pores enclosed by the blue square in (2), and the image of (2) shows magnified images of the pores enclosed by the blue square in (1).

Sample $\mathrm{C}$ is a PMP membrane, and the unique pore structure is different from Figures 3 and 4 . The inner surface of the membrane has the unique mountain-range structure that includes pores. The outer surface of the membrane is highly porous compared to the inner surface of the membrane. The three-dimensional unevenness of the outer surface of the membrane is considerably larger than the inner surface, but in principle for the FE-SEM, it is difficult to obtain three-dimensional information using the FE-SEM.

In addition, Figure 7 is the image of a different sample taken from the same device. The pore structure on the outer surface of Figure 7 is completely different from that of Figure 6. Many samples had structures similar to the image in Figure 7, but some had structure similar to Figure 6. This is as the skin layer as shown in Figure 7 is formed during the formation (melt-spinning method) of the PMP membrane.

As described above, in this study, the unique pore structures of ECMO membranes, which are commonly used in Japan and worldwide, are clarified in detail for the first time using FE-SEM. In particular, each membrane has completely different anisotropic pore structure on the inner and outer surfaces of the membrane. Extracorporeal membrane oxygenator, which is the outside blood flow type, is the mainstream of membrane oxygenator [22-27]. Therefore, it is necessary to appropriately design the pore structure on the outer surface of the membrane that comes into direct contact with blood and the pore structure on the inner surface of the membrane that comes into contact with gas. For this purpose, it is important to control the anisotropic structure of the cross-section of the membrane. 
(a1)

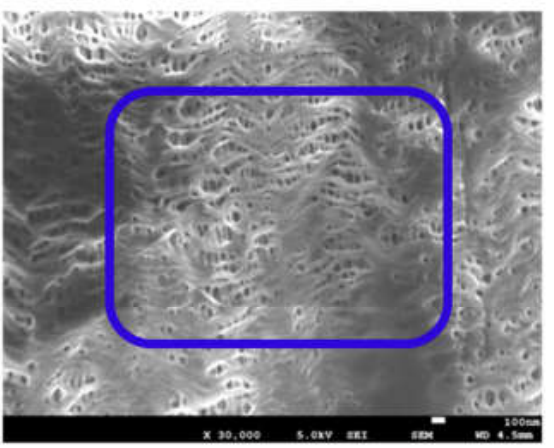

(b1)

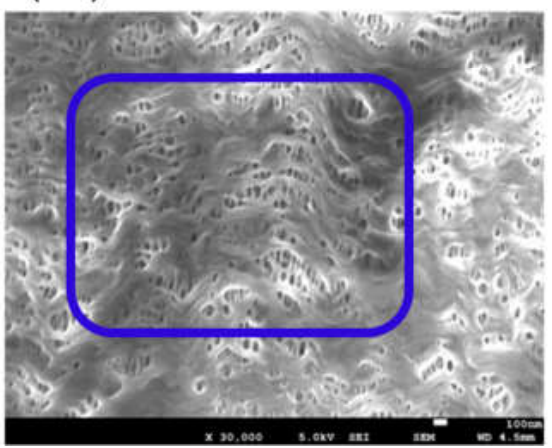

(a2)

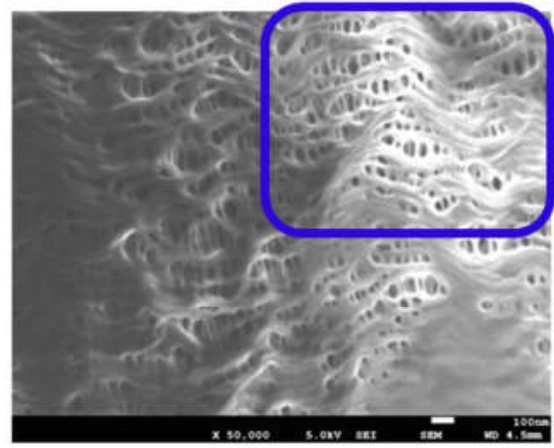

(b2)

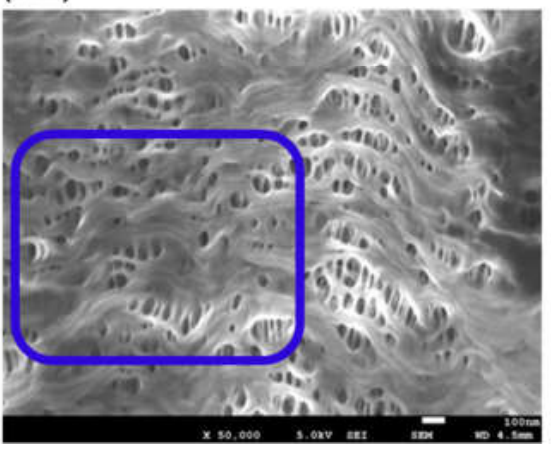

(a3)

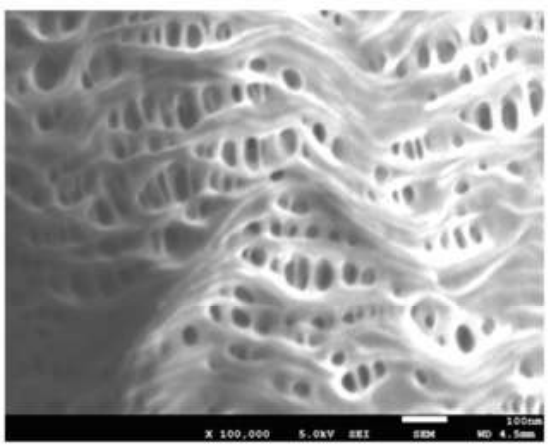

(b3)

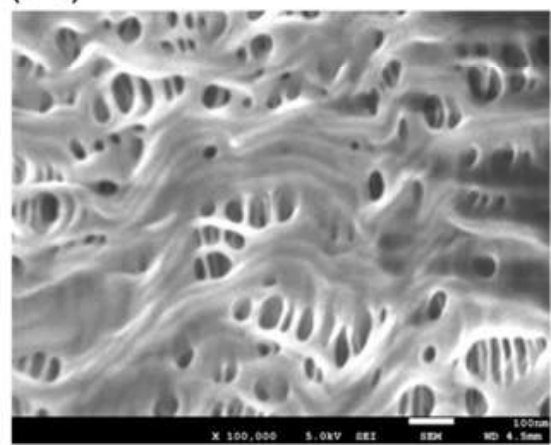

Figure 7. FE-SEM images of $\operatorname{BIOCUBE}^{\circledR}(\mathrm{dry}),(\mathbf{a})$ the surface of inner lumen of the capillary membranes and (b) the outer surface of the capillary membranes: (1) $\times 30,000$; (2) $\times 50,000$; and (3) $\times 100,000$, respectively. The image of (3) shows magnified images of the pores enclosed by the blue square in (2), and the image of (2) shows magnified images of the pores enclosed by the blue square in (1).

\subsection{Measurement of Pore Diameter and Pore Diameter Distribution and Evaluation of SARS-CoV-2 Permeability}

For a pore diameter measurement, pores that were measured in observation fields of a magnification of 100,000 in size were analyzed. As none of the pores were true circles, the major and minor axis of the pores were measured through a line length analysis. Figure 8 shows the distributions of pore diameters.

Table 2 shows the values for the pore diameter of the ECMO membranes. The pore diameter on the outer surface of sample B was described as a reference as there were only five sets of data that could be observed after the silicone layer was peeled off. Furthermore, the partition coefficient and intramembrane diffusion coefficient of SARS-CoV-2 calculated using the steric exclusion model and the hindered diffusion model described in 2.4 are also shown in Table 2.

In Figure 8 and Table 2, the pore diameters on the outer surfaces of the membranes are smaller than those on the inner surfaces of the membranes. It is necessary to verify what kind of spinning process creates the unique pore structure of each membrane. 
oxia $\circledR$

(a1)

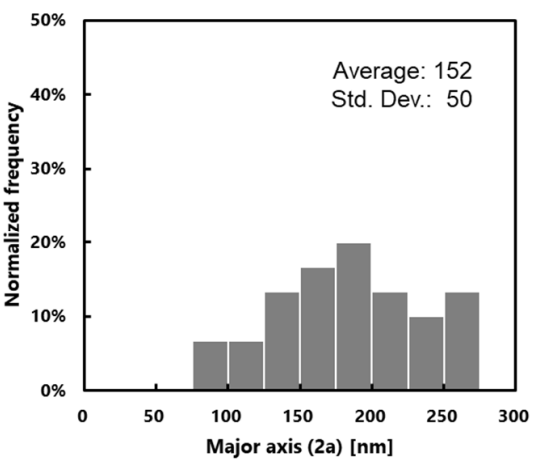

(a'1)

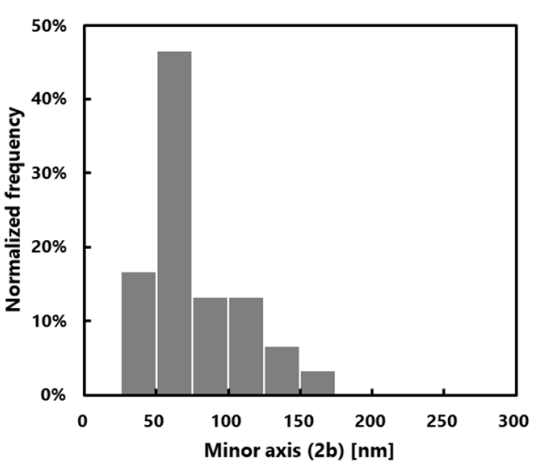

(b1)
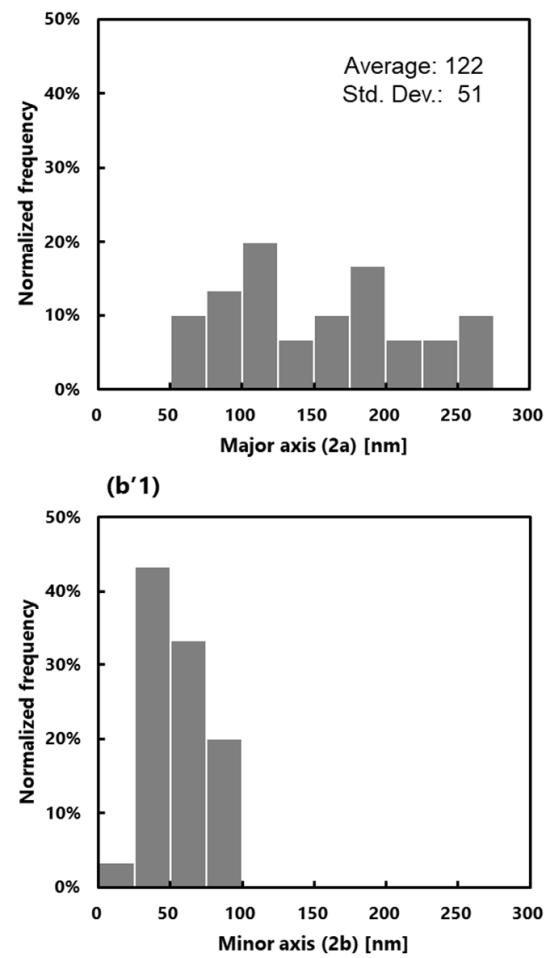

MERA NHP

BIOCUBE®

(a1)

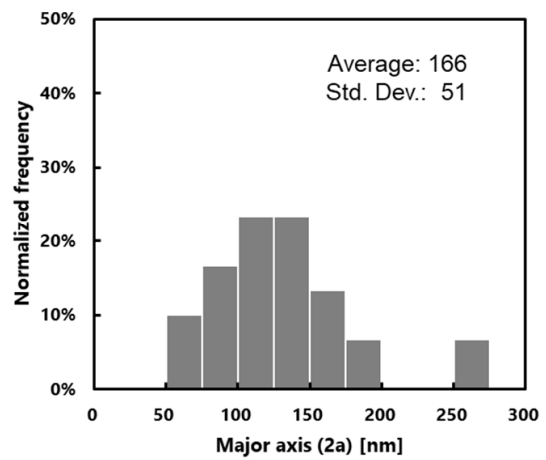

(a'1)

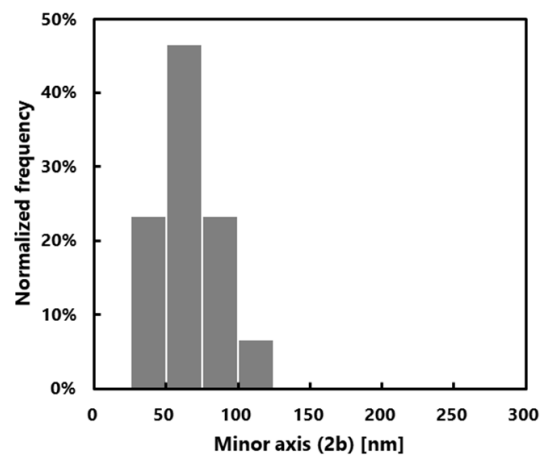

(b1)
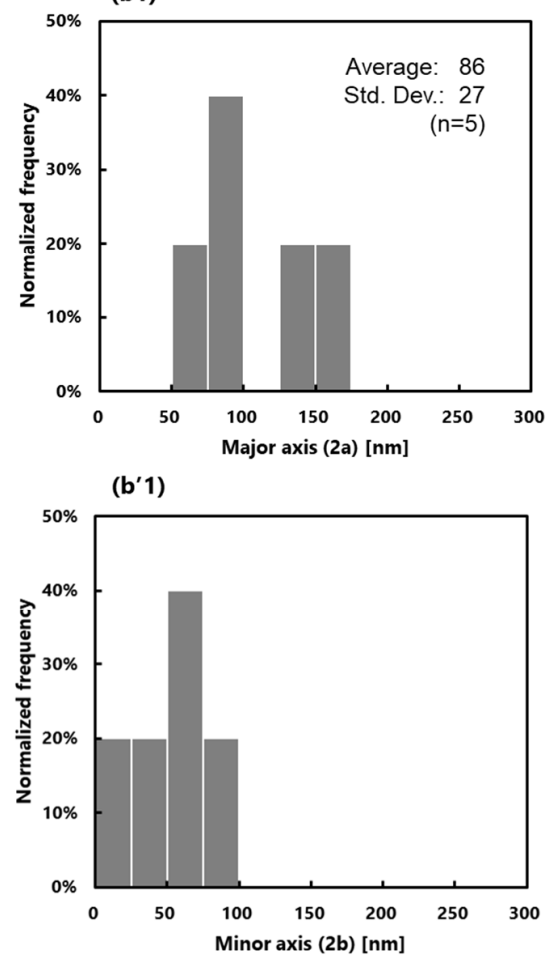

(a1)

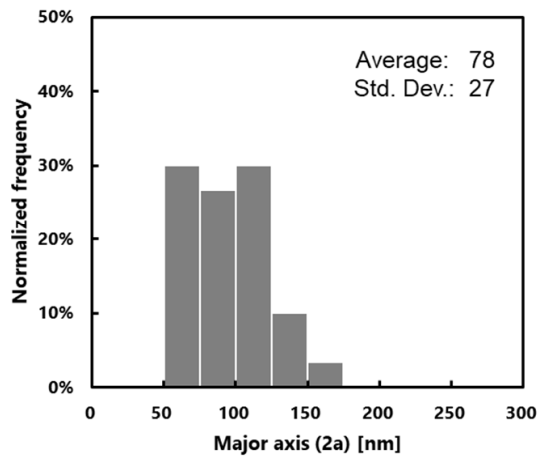

(a'1)

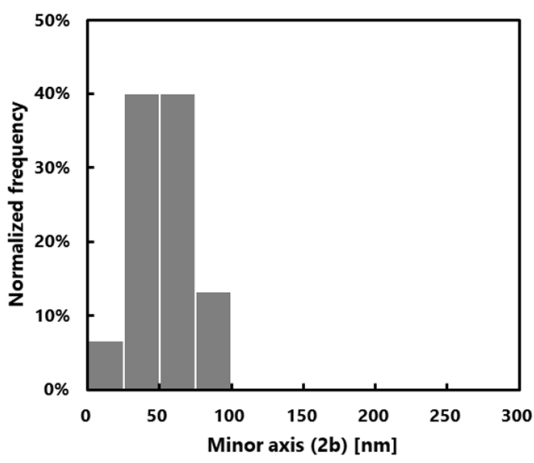

(b1)

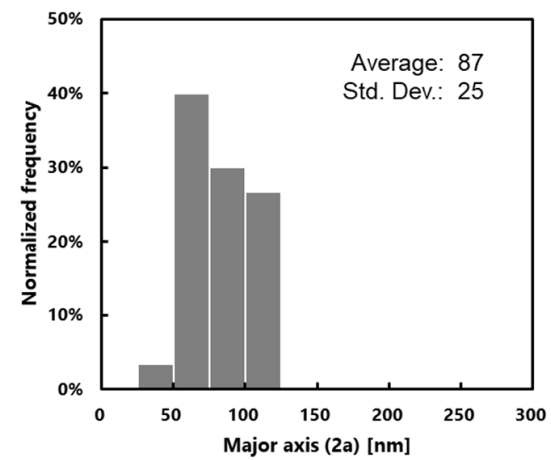

(b'1)

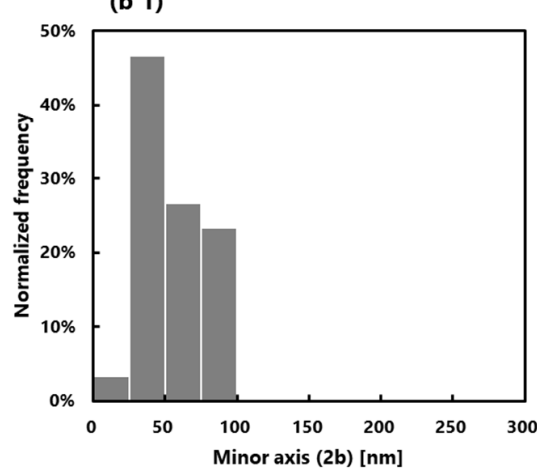

Figure 8. Distribution of the ellipse pore diameter of three membranes (dry), determined via FE-SEM, (a) the surface of inner lumen of the capillary membranes and (b) the outer surface of the capillary membranes. (a1,b1) Major axis (2a), $\left(\mathbf{a}^{\prime} \mathbf{1}, \mathbf{b}^{\prime} \mathbf{1}\right)$ Minor axis (2b). 
Table 2. Pore diameter of ECMO membranes and SARS-CoV-2 permeability.

\begin{tabular}{|c|c|c|c|}
\hline Sample & $\begin{array}{c}\text { Oxia }^{\circledR} \text { ACF } \\
\text { Sample A }\end{array}$ & $\begin{array}{l}\text { MERA NHP }{ }^{\circledR} \text { Exelung } \\
\text { TPC HPO-23WH-C } \\
\text { Sample B }\end{array}$ & $\begin{array}{l}\text { BIOCUBE }^{\circledR} 6000 \\
\text { Sample C }\end{array}$ \\
\hline \multirow{2}{*}{$\begin{array}{l}\text { Tortuous pore diameter of inner surface }(\mathrm{nm}) \mathrm{n}=50, \mathrm{AVG} . \pm \text { STD. } \\
\text { upper: major axis } \\
\text { lower: minor axis }\end{array}$} & $152 \pm 50$ & $166 \pm 51$ & $78 \pm 27$ \\
\hline & $59 \pm 25$ & $53 \pm 15$ & $42 \pm 13$ \\
\hline \multirow{2}{*}{$\begin{array}{l}\text { Tortuous pore diameter of outer surface }(\mathrm{nm}) \mathrm{n}=50, \text { AVG. } \pm \text { STD. } \\
\text { upper: major axis } \\
\text { lower: minor axis }\end{array}$} & $122 \pm 51$ & $86 \pm 27$ & $77 \pm 25$ \\
\hline & $44 \pm 14$ & $40 \pm 18(n=5)$ & $52 \pm 15$ \\
\hline \multirow{2}{*}{$\begin{array}{c}\text { Partition coefficient (K) of SARS-CoV-2 [-] } \\
\text { SARS-CoV-2 diameter } \\
\text { upper: } 50 \mathrm{~nm} \\
\text { lower: } 80 \mathrm{~nm} \\
\end{array}$} & 0.35 & 0.18 & 0.12 \\
\hline & 0.12 & 0.005 & 0.002 \\
\hline \multirow{2}{*}{$\begin{array}{l}\text { Intramembrane diffusive coefficient }\left(\mathrm{D}_{\mathrm{m}}\right) \text { of SARS-CoV-2 }{ }^{(1)}(2)\left(\mathrm{m}^{2} / \mathrm{s}\right) \\
\text { SARS-CoV- } 2 \text { diameter } \\
\text { upper: } 50 \mathrm{~nm} \\
\text { lower: } 80 \mathrm{~nm} \\
\end{array}$} & $7.2 \times 10^{-13}$ & $1.6 \times 10^{-13}$ & $8.9 \times 10^{-14}$ \\
\hline & $5.5 \times 10^{-14}$ & $1.5 \times 10^{-15}$ & $8.4 \times 10^{-17}$ \\
\hline
\end{tabular}

(1) $\mathrm{D}_{\mathrm{m}}$ was calculated with the tortuousity on the outer surface side of the membrane as 1 . It needs to be modified in the future. (2) Calculated glucose diffusion coefficient $4.7 \times 10^{-10} \mathrm{~m}^{2} / \mathrm{s}, 9.3 \times 10^{-10} \mathrm{~m}^{2} / \mathrm{s}$ (the value in the literature) [19].

The diameter of SARS-CoV-2 is said to be $50-200 \mathrm{~nm}$ [28]. Table 2 shows the partition coefficient and the intramembrane diffusive coefficient calculated with the diameter of SARS-CoV-2 at $50 \mathrm{~nm}$ and $80 \mathrm{~nm}$ which were smaller than the pore diameter. The partition coefficients are greater than 0 , intramembrane diffusion coefficients of SARS-CoV-2 are $8.9 \times 10^{-14}-7.2 \times 10^{-13} \mathrm{~m}^{2} / \mathrm{s}$. Therefore, when a plasma leakage occurs in an extracorporeal membrane oxygenator, SARS-CoV-2 also permeates through the pores of the membrane with the filtration flow of the plasma from the outside to the inner lumen of the membrane. The risk of SARS-CoV-2 permeation in Sample B and Sample C were lower than that of Sample A. The risk of SARS-CoV-2 permeation is completely different due to each anisotropic pore structure, and certainly chemical property. Glucose diffusion coefficient in water calculated by this model is $4.7 \times 10^{-10} \mathrm{~m}^{2} / \mathrm{s}$, while the value in the literature is $9.3 \times 10^{-10} \mathrm{~m}^{2} / \mathrm{s}$. From these data, the credibility of the values calculated by the model is not perfect, but it is reasonably sufficient. The transfer rate of SARS-CoV-2 in the membrane is about $1 / 1000$ of the transfer rate of glucose in water.

\section{Discussion}

\subsection{ECMO Infection and Usefulness of Theoretically Validating SARS-CoV-2 Permeation through Membrane}

Serious dysfunctions in extracorporeal membrane oxygenator are excessive pressure drop in blood flow path due to blood coagulation and thrombosis, and plasma leakage [4-8]. Plasma leakage occurs in extracorporeal membrane oxygenation over a longer term. When a plasma leakage occurs, not only is the gas exchange efficiency is lowered, but the water balance of the patient is also disturbed, and in the worst case, there is a concern that the patient may be in critical condition.

During the current COVID-19 pandemic, it has been reported that the plasma components from the gas outlet port of the membrane oxygenator became yellow foam and positive PCR test results were obtained from the gas outlet port of the membrane oxygenator $[2,29]$. This is due to the fact that SARS-CoV-2 in plasma may permeate the hollow fiber membrane and aerosol diffusion occurs from the gas outlet port [29]. Therefore, in ECMO support for COVID-19 patients, it must be recognized that there is the risk of ECMO infection due to extra-circulatory spread of the SARS-CoV-2. Moreover, there is a concern that, if the blood coagulation and thrombus are generated in severely ill patients with COVID-19 [9] and they cause a more serious excessive pressure drop, then the transmembrane pressure (TMP) is increased, and plasma and virus easily permeate through the membrane. As the inner lumen of hollow fiber is filled with gas, the TMP is larger than that of the dialyzer in which the inner lumen of hollow fiber is filled with 
blood. With these concerns, medical staff always use N95 masks, gowns, caps, and face shields to prevent infection with SARS-CoV-2 during ECMO support. Medical staff are burdened by serious pandemic. However, there was no direct evidence of how such a SARS-CoV-2 infection phenomenon occurred. In particular, there is the need to verify the risk of SARS-CoV-2 leakage through PMP membrane and silicone-coated membrane, and to examine the damaged membranes [29].

Therefore, in this study, from the viewpoint of membrane science, we analyzed the recent common ECMO membranes used in Japan and worldwide. The precise pore structure of the membranes was elucidated by direct microscopic observation using FESEM. The pore structure of the hollow fiber membrane is not homogeneous but asymmetric. As the pore structures on the inside and the outside of the membrane are different, if the pores on the outside of the membrane are highly microporous, SARS-CoV-2 penetrates from the outside to the inside of the hollow fiber lumen. Here, we find that SARS-CoV-2 may permeate the membrane, transfer from the patient's blood to the gas side, and diffuse from the gas side outlet port of ECMO. Even in the case of a membrane that suppresses plasma leakage using a silicone-coated membrane such as sample B, plasma leakage may occur due to silicone layer peeled off. In addition, when plasma does not permeate the silicone layer, but gas (water vapor) permeates the silicone layer. Furthermore, condensation (wet lung) occurs in the gas side (inner lumen of hollow fiber) due to a change in the temperature of the gas side, and porous pores on inner lumen are filled with water. In these cases, SARS-CoV-2 is also likely to permeate the membrane wall, even if plasma leakage does not occur. These increase the risk of ECMO infection caused by extra-circulatory spread of the SARS-CoV-2. Additionally, the risk of ECMO infection may be quantitatively evaluated from the viewpoint of membrane science.

In terms of regulatory approval, a PMP membrane with a dense outer layer has been approved for 30 days usage for ECMO (CE marking), whether the plasma leakage is completely prevented requires further study [30]. The FDA has urgently approved the use of ECMO for up to 15 days. In Japan, ECMO is approved for use up to $6 \mathrm{~h}$ only. The package inserts for the three samples in this study also state that plasma leakage may occur.

\subsection{Optimal Design of Asymmetrical Pore Structure of ECMO Membrane}

From these perspectives, it is necessary to appropriately design the pore structure on the outer side of the membrane that comes into direct contact with blood as well as the pore structure on the inner side of the membrane that comes into contact with gas. It is important to control the anisotropic structure of the membrane cross-section.

We also focus on the fouling during ECMO treatment [16]. As a next-generation membrane with long-term durability, fouling does not proceed easily, and SARS-CoV-2 does not easily penetrate to prevent extra-circulatory spread of the SARS-CoV-2. These three membranes in this study are contributing to cardiovascular surgery and support for severe acute respiratory distress syndrome, both in Japan and worldwide. Plasma leakage has always been an issue, and its importance is once again recognized due to the current COVID-19 pandemic. In the future, it is necessary to develop next-generation membranes and systems with long-term durability suitable for treatment [31] of COVID-19 critically ill patients. Microstructured hollow fiber membranes that increase the gas exchange surface area were also proposed to improve oxygenator performance [32].

\subsection{Limitations of Theoretically Validating SARS-CoV-2 Permeation Based on the Membrane Transport Model}

In this study, we attempted to evaluate the SARS-CoV-2 permeability using the steric exclusion model and the hindered diffusion model [19] for transport phenomena in membrane. These are fundamental and valuable models for simply calculating the SARS-CoV-2 permeability based on the data listed in Table 2 .

However, in this study, data such as the molecular weight distribution, diffusion coefficient in a fluid or quiescent fluid and physical properties of SARS-CoV-2, its affinity with membrane and concentration in plasma have not been available. As soon as such data 
are accumulated, more detailed validations are feasible. Additionally, there is no actual data on the SARS-CoV-2 permeation, as the suitability of using SARS-CoV-2 in vitro is questionable. To study actual virus permeation, an approach of directly observing virus permeation through membrane wall [33] is also useful.

On the other hand, medical staff are doing rigorous work day by day, so direct evidence is required as described above. Although the output of our study may not provide direct evidence, it provides novel insights to ECMO support of COVID-19 critically ill patients. From our research and other studies [2,29], SARS-CoV-2 is highly likely to permeate the membrane transporting from the patient's blood to the gas side, and may diffuse from the gas side outlet port of ECMO.

\section{Conclusions}

The precise pore structures of the ECMO membranes were clarified by direct microscopic observation by FE-SEM. The three types of membranes, polypropylene membrane, polypropylene membrane coated with thin silicone layer, and polymethylpentene (PMP) membrane, each have a unique pore structure, and the pore structures on the inner and outer surfaces of the membranes are completely different anisotropic structures. When plasma leakage occurs during long-term prolonged ECMO treatment, SARS-CoV-2 is also likely to permeate through uniquely shaped anisotropic pores with the filtration flow of plasma or wet lung. In this case, SARS-CoV-2 is discharged from the outlet port of the oxygenator gas side, so care must be taken to prevent airborne transmission and aerosol infections of SARS-CoV-2. The risk of SARS-CoV-2 permeation in polypropylene membrane coated with thin silicone layer (Sample B) and PMP membrane (Sample C) was lower. At the time of this current COVID-19 pandemic, the risk of infections on the operators of medical devices is drawing attention. In the future, development of next-generation extracorporeal membrane oxygenator and system with long-term durability is envisaged.

Author Contributions: M.F.: concept, design of the experiment, performed the experiment, data analysis/interpretation, and wrote the paper. T.F.: design of the experiment and data analysis/interpretation. K.S. (Kazunori Sadano): design of the experiment and data analysis/interpretation. A.T.: design of the experiment and data analysis/interpretation. T.M.: design of the experiment and data analysis/interpretation. H.S.: design of the experiment and data analysis/interpretation. K.S. (Kiyotaka Sakai): concept, design of the experiment, data analysis/interpretation, and wrote the paper. All authors have read and agreed to the published version of the manuscript.

Funding: This research received no external funding.

Institutional Review Board Statement: Not applicable.

Informed Consent Statement: Not applicable.

Acknowledgments: The authors gratefully thank Naomi Backes Kamimura (Kindai University) for helpful suggestions during preparation of the manuscript.

Conflicts of Interest: The other authors have no conflict of interest to declare.

\section{Abbreviations}

$$
\begin{aligned}
& C^{a} \\
& C_{\text {Apore }} \\
& C_{\text {Abulk }}^{x=0} \\
& D_{A B} \\
& D_{m} \\
& D_{\text {pasma }} \\
& D_{\text {pore }}
\end{aligned}
$$

Molecular radius, Solute radius (m)

Concentration $\left(\mathrm{g} / \mathrm{m}^{3}\right)$

Concentration in a pore $\left(\mathrm{mg} / \mathrm{m}^{3}\right)$

solute concentration in the pore at the inlet of the pore related with the

bulk solute concentration $\left(\mathrm{mg} / \mathrm{m}^{3}\right)$

Diffusion coefficient in a homogeneous fluid, usually used for water at $37^{\circ} \mathrm{C}\left(\mathrm{m}^{2} / \mathrm{s}\right)$

Diffusion coefficient in membrane $\left(\mathrm{m}^{2} / \mathrm{s}\right)$

Diffusion coefficient in plasma $\left(\mathrm{m}^{2} / \mathrm{s}\right)$

Diffusion coefficient in a pore $\left(\mathrm{m}^{2} / \mathrm{s}\right)$ 


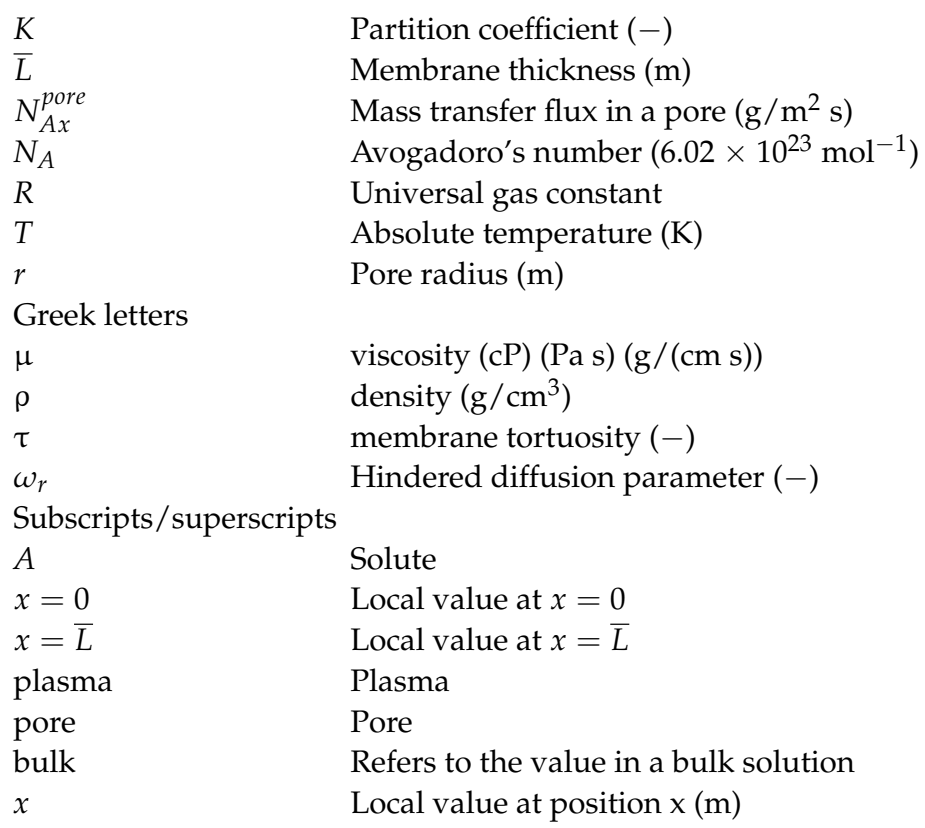

\section{References}

1. Japan ECMO Network, Japanese Association for Acute Medicine, the Japanese Society of Intensive Care Medicine, Japanese Society of Respiratory Care Medicine, The Japanese Association for Infectious Diseases, The Japanese Respiratory Society, Japanese Society of Percutaneous Cardio-Pulmonary Support/Extracorporeal Membrane Oxygenation. Available online: https: //www.ecmonet.jp (accessed on 1 July 2021).

2. Keibun, L. An Assessment of Aerosolization via Membranous Oxygenator and Coagulopathy in COVID-19. ELSO Webinar, 2020.3.30. Available online: https:/ / ecmoedblog.files.wordpress.com/2020/03/elso-webinar-slides-keibun-liu.pdf (accessed on 1 April 2021).

3. Hagiwara, K.; Innami, K.; Yokoyama, K.; Kitoh, H.; Muramoto, T.; Tatebe, K.; Seita, Y.; Fukasawa, H. An approach to the microporous hollow fiber for the ECMO oxygenator-Micopore characterization of the gas exchange performance, plasma leakage, and hydrophilization of the inner surface of fibers. Jpn. J. Artif. Organs 1992, 21, 720-726. (In Japanese)

4. Lund, L.W.; Hattler, B.G.; Federspiel, W.J. Is condensation the cause of plasma leakage in microporous hollow fiber membrane oxygenators. J. Membr. Sci. 1998, 147, 87-93. [CrossRef]

5. Meyns, B.; Vercaemst, L.; Vandezande, E.; Bollen, H.; Vlasselaers, D. Plasma leakage of oxygenators in ECMO depends on the type of oxygenator and on patient variables. Int. J. Artif. Organs 2005, 28, 30-34. [CrossRef]

6. Fisher, A.R.; Baker, M.; Buffin, M.; Campbell, P.; Hansbro, S.; Kennington, S.; Lilley, A.; Whitehorne, M. Normal and abnormal trans-oxygenator pressure gradients during cardiopulmonary bypass. Perfusion 2003, 18, 25-30. [CrossRef] [PubMed]

7. Myers, G.J.; Weighell, P.R.; McCloskey, B.J.; Holt, A.M.; McTeer, S.; Maxwell, S.L. A multicenter investigation into the occurrence of high-pressure excursions. J. Extra. Corpor. Technol. 2003, 35, 127-132. [PubMed]

8. Ündar, A.; Owens, W.R.; McGarry, M.C.; Surprise, D.L.; Kilpack, V.D.; Mueller, M.W.; McKenzie, E.D.; Fraser, J.C.D. Comparison of hollow-fiber membrane oxygenators in terms of pressure drop of the membrane during normothermic and hypothermic cardiopulmonary bypass in neonates. Perfusion 2005, 20, 135-138. [CrossRef]

9. Levi, M.; Thachik, J.; Iba, T.; Levy, J.H. Coagulation abnormalities and thrombosis in patients with COVID-19. Lancet Haematol. 2020, 7, e438-e440. [CrossRef]

10. Sakai, K.; Takesawa, S.; Mimura, R.; Ohashi, H. Determination of pore radius of hollow fiber dialysis membranes using tritium-labeled water. J. Chem. Eng. Jpn. 1988, 21, 207-210. [CrossRef]

11. Sakai, K. Determination of pore size and pore size distribution: 2. Dialysis membranes. J. Membr. Sci. 1994, 96, 91-130. [CrossRef]

12. Hayama, M.; Kohori, F.; Sakai, K. AFM observation of small surface pores of hollow fiber dialysis membrane using highly sharpened probe. J. Membr. Sci. 2002, 197, 243-249. [CrossRef]

13. Yamamoto, K.-I.; Hayama, M.; Matsuda, M.; Yakushiji, T.; Fukuda, M.; Miyasaka, T.; Sakai, K. Evaluation of asymmetrical structure dialysis membrane by tortuous capillary pore diffusion model. J. Membr. Sci. 2007, 287, 88-93. [CrossRef]

14. Yamazaki, K.; Matsuda, M.; Yamamoto, K.-I.; Yakushiji, T.; Sakai, K. Internal and surface structure characterization of cellulose triacetate hollow fiber dialysis membranes. J. Membr. Sci. 2011, 368, 34-40. [CrossRef]

15. Fukuda, M.; Saomoto, H.; Mori, T.; Yoshimoto, H.; Kusumi, R.; Sakai, K. Impact of three-dimensional tortuous pore structure on polyethersulfone membrane morphology and mass transfer properties from a manufacturing perspective. J. Artif. Organs 2020, 23, 171-179. [CrossRef] [PubMed] 
16. Fukuda, M.; Yoshimoto, H.; Saomoto, H.; Sakai, K. Validity of three-dimensional tortuous pore structure and fouling of hemoconcentration capillary membrane using the tortuous pore diffusion model and scanning probe microscopy. Membranes 2020, 10, 315. [CrossRef]

17. Ministry of Health, Labor and Welfare. Reiwa 2nd Year of Score Table for Medical Fee, Disposable Oxygenator (Membrane Oxygenator), Extracorporeal Membrane Oxygenator for Assisting Respiration; Ministry of Health, Labor and Welfare: Tokyo, Japan, 2020. (In Japanese)

18. ISO5636-5(2013). Paper and Board-Determination of Air Permeance (Medium Range)—Part 5: Gurley Method; ISO Technical Committee: Geneva, Switzerlnd, 2013.

19. Fournier, R.L. Chapter 6 Mass transfer in heterogeneous materials. In Basic Transport Phenomena in Biomedical Engineering, 4th ed.; Fournier, R.L., Ed.; CRC Press: Boca Raton, FL, USA, 2017; pp. 289-347.

20. Beck, R.E.; Schultz, J.S. Hindered diffusion in microporous membranes with known pore geometry. Science 1970, 170, 1302-1305. [CrossRef]

21. Deen, W.M. Hindered transport of large molecules in liquid-filled pores. AIChE J. 1987, 33, 1409-1425. [CrossRef]

22. Matsuda, N.; Sakai, K. Blood flow and oxygen transfer rate of an outside blood flow membrane oxygenator. J. Membr. Sci. 2000, 170, 153-158. [CrossRef]

23. Matsuda, N.; Sakai, K.; Yamamoto, K.-I.; Iwasaki, H. Effects of hollow fiber packing fraction on blood flow pattern and gas transfer rate of an intravascular oxygenator (IVOX). J. Membr. Sci. 2000, 179, 231-241. [CrossRef]

24. Catapano, G.; Hornsceidt, R.; Wodetzki, A.; Baurmeister, U. Turbulent flow technique for the estimation of oxygen diffusive permeability of membranes for the oxygenation of blood and other cell suspensions. J. Membr. Sci. 2004, 230, 131-139. [CrossRef]

25. Zhang, J.; Nolan, T.D.C.; Zhang, T.; Griffith, B.P.; Wu, Z.J. Characterization of membrane blood oxygenation devices using computational fluid dynamics. J. Membr. Sci. 2007, 288, 268-279. [CrossRef]

26. Tabesh, H.; Amoabediny, G.; Poorkhalil, A.; Khaschab, A.; Kashefi, A.; Mottaghy, K. A theoretical model for evaluation of the design of a hollow fiber membrane oxygenator. J. Artif. Organs 2012, 15, 347-356. [CrossRef]

27. Fukuda, M.; Tokumine, A.; Noda, K.; Sakai, K. Newly developed pediatric membrane oxygenator that suppresses excessive pressure drop in cardiopulmonary bypass and extracorporeal membrane oxygenation (ECMO). Membranes 2020, 10, 362. [CrossRef]

28. Chen, N.; Zhou, M.; Dong, X.; Qu, J.; Gong, F.; Han, Y.; Qiu, Y.; Wang, J.; Liu, Y.; Wei, Y.; et al. Epidemiological and clinical characteristics of 99 cases of 2019 novel coronavirus pneumonia in Wuhan, China: A descriptive study. Lancet 2020, 395, 507-513. [CrossRef]

29. Ogawa, T.; Uemura, T.; Matsuda, W.; Sato, M.; Ishizuka, K.; Fukaya, T.; Kinoshita, N.; Nakamoto, T.; Ohmagari, N.; Katano, H.; et al. SARS-CoV-2 Leakage from the Gas Outlet Port during Extracorporeal Membrane Oxygenation for COVID-19. ASAIO J. 2021, 67, 511-516. [CrossRef] [PubMed]

30. Gill, M.C.; Shaughnessy, K.O.; Dittmer, J. A pediatric ECMO case of plasma leakage through a polymethylpentene oxygenator. Perfusion 2015, 30, 600-603. [CrossRef] [PubMed]

31. Arens, J.; Grottke, O.; Haverich, A.; Maier, L.S.; Schmitz-Rode, T.; Steinseifer, U.; Wendel, H.P.; Rossaint, R. Toward a Long-Term Artificial lung. ASAIO J. 2020, 847-854. [CrossRef] [PubMed]

32. Ecker, P.; Pekovits, M.; Yorov, T.; Haddadi, B.; Lukitsch, B.; Elenkov, M.; Janeczek, C.; Jordan, C.; Gfoehler, M.; Harasek, M. Microstructured hollow fiber membranes; Potential fiber shapes for extracorporeal membrane oxygenatiors. Membranes 2021, 11, 374. [CrossRef] [PubMed]

33. Ayano, M.; Sawamura, Y.; Hongo-Hirasaki, T.; Nishizaka, T. Direct visualization of virus removal process in hollow fiber membrane using an optical microscope. Sci. Rep. 2021, 11, 1-9. [CrossRef] 